\title{
Diffusion and mobility of native point defects in narrow-gap $\mathrm{Hg}_{1-\mathrm{x}} \mathrm{Cd}_{\mathrm{x}} \mathrm{Te}$ crystals
}

\author{
V.V. Bogoboyashchyy ${ }^{1}$, A.I. Elizarov ${ }^{1}$, K.R. Kurbanov ${ }^{2}$ \\ ${ }^{1}$ Kremenchuk State Polytechnical University, 20 Pershotravneva st., 39614 Kremenchuk Ukraine \\ Phone: +38(0536) 77 6718, fax: +38(05366) 36000, e-mail: bob@kremen.ukrtel.net \\ ${ }^{2}$ Institute of Economy and New Technologies, 24/37 Proletars'ka st., 39614 Kremenchuk, Ukraine \\ Phone: +38(05366) 36296,e-mail: ient@kremen.ukrtel.net
}

\begin{abstract}
Results of investigations of mercury vacancy diffusion in the narrow-gap $\mathrm{Hg}_{1-\mathrm{x}} \mathrm{Cd}_{\mathrm{x}} \mathrm{Te}$ crystals are presented. A new theory for mercury diffusion in a gradient of native defect concentration is proposed. The theory takes into account the effect of charged defect drift in the internal electric field arising in the crystal at such process. Using this theory, the mercury vacancy diffusion coefficient in the $\mathrm{Hg}_{1-\mathrm{x}} \mathrm{Cd}_{\mathrm{x}} \mathrm{Te}(\mathrm{x} \sim 0.2)$ crystals at $384-690 \mathrm{~K}$ has been found: $D_{V}=0.0063 \exp \left(-0.85 \mathrm{eV} / k_{B} T\right) \mathrm{cm}^{2} / \mathrm{s}$. The result is found by fitting the experimental diffusion distribution of the vacancies obtained by a reliable optical method of local free carrier concentration measurements, on the one hand, and data of vacancy coagulation rate measurements, on the other hand. The mercury vacancy diffusion runs rather slowly at $T<690 \mathrm{~K}$
\end{abstract}

Keywords: superconductors, $\mathrm{Hg}_{1-\mathrm{x}} \mathrm{Cd}_{\mathrm{x}} \mathrm{Te}$, point defects, diffusion.

Paper received 24.12.02; accepted for publication 18.03.03.

\section{Introduction}

Efficient control of properties of the narrow-gap $\mathrm{Hg}_{1-\mathrm{x}} \mathrm{Cd}_{\mathrm{x}} \mathrm{Te}(\mathrm{MCT})$ thin films and bulk crystals, based on convertible change of active native defects concentration by mercury diffusion, is the major part of a technology of obtaining photosensitive structures of the material [1;2]. Efficiency of such control is determined by accuracy of data both about reaction constants of the defects, and about their diffusion coefficients. Now the first group of the characteristics is quite deeply investigated both experimentally and theoretically [3-8]. It has been found, that twice ionized mercury vacancies $\left(V_{H g}{ }^{\prime \prime}\right)$ are the basic equilibrium native defects in the MCT crystals, annealed at $T>570 \mathrm{~K}$, and the amount of other native defects is rather small [3-8].

Nevertheless, it appears, that mercury interstitials $\mathrm{Hg}_{I}{ }^{\prime \prime}$ due to its extremely high mobility actively participates in mercury diffusion in the MCT crystals, determining a flow of the substance at high $\mathrm{Hg}$ vapour pressures $[2 ; 9-12]$. The mechanism of the process was specified in [10-11]: concentration Hg diffusion in MCT crystals occurs to participation both $\mathrm{Hg}_{I}{ }^{\prime \prime}$, and $V_{H g}{ }^{\prime \prime}$ intensively cooperating quasi-chemically with each other. On the other hand, the role of the mercury vacancy diffusion in this phenomenon meanwhile is not clear up to the end, as there is not enough direct experimental data about it, and they are rather inconsistent [2].

The elementary theoretical models for such mercury diffusion in MCT for the first time were offered in Refs. [10-11]. In Ref. [10] a semi-empirical theory for $\mathrm{Hg}$ diffusion in strongly Te-oversaturated heterogeneous MCT crystals is described, and in Ref. [11] a theory for $\mathrm{Hg}$ diffusion in the homogeneous material, constructed on application of the method of stationary concentration well-known in chemical kinetics, is submitted. The theory of the process further has been developed in Refs. [1213]. In particular, in Ref. [13] an approach is formulated to elaboration of a model for mercury in-diffusion into heterogeneous MCT crystals at any tellurium excess. In the same place experimental structures of mercury vacancy distribution are submitted for a case of deep mercury diffusion and their diffusion coefficient is determined on the basis of application of such model; the reasons of disagreements on this problem are also discussed there.

The listed above models well describe experimentally observably features of $\mathrm{Hg}$ diffusion in MCT, however any of them does not take into account the phenomenon 


\section{V.V. Bogoboyashchyy et al.: Diffusion and mobility of native point defects ...}

of drift of the charged point defects in the electric field arising in a gradient of concentration of such defects. On the other hand, at high temperatures in saturated and over-saturated with tellurium MCT crystals when the contribution of the vacancy mechanism is swept up enough, the amount of the active defects in MCT is great in comparison with free carriers amount [8]. Accordingly, the neglect drift of the defects leads to significant mistakes at determination of the diffusion coefficients.

Therefore a new model is offered here. The model takes into account both $\mathrm{Hg}_{I}{ }^{\prime \prime}$ and $V_{H g}$ " diffusion, and drift of these charged defects in the electric field arising in a gradient of their concentration at $\mathrm{Hg}$ diffusion with a resulting flow of the substance. Within framework of this model the diffusion structures of $V_{\mathrm{Hg}}$ " distribution are analyzed in the thick (3-4 mm) monocrystalline MCT plates, obtained earlier by one of the authors and submitted in Ref. [13], and the vacancy diffusion coefficient is determined in the appropriate temperature range. The results are compared to data of Ref. [14] where kinetics of Te precipitate formation has been investigated theoretically and experimentally at low-temperature annealing Te-oversaturated MCT crystals. It has been shown there, that the process rate is limited with the vacancy diffusion.

\section{Model}

The model offered here will improve the theory offered in [10-13], by the account of drift of the native defects in a gradient of electric potential created by them. According to such approach the system of the equations describing mercury diffusion on the mixed vacancy-interstitial mechanism, gets the following kind:

$$
\begin{aligned}
& \frac{\partial}{\partial t}\left[V_{H g}^{\prime \prime}\right]-D_{V} \frac{\partial^{2}}{\partial z^{2}}\left[V_{H g}^{\prime \prime}\right]+2 D_{V} \frac{\partial}{\partial z}\left(\left[V_{H g}^{\prime \prime}\right] \frac{\partial}{\partial z} \frac{e \varphi}{k T}\right)= \\
& =k_{F}\left(K_{F}-\left[V_{H g}^{\prime \prime}\right] \cdot\left[H g_{I^{\prime \prime}}\right]\right) ; \\
& \frac{\partial}{\partial t}\left[H g_{I^{\prime \prime}}\right]-D_{I} \frac{\partial^{2}}{\partial z^{2}}\left[H g_{I^{\prime \prime}}\right]-2 D_{I} \frac{\partial}{\partial z}\left(\left[H g_{I^{\prime \prime}}\right] \frac{\partial}{\partial z} \frac{e \varphi}{k T}\right)= \\
& =k_{F}\left(K_{F}-\left[V_{H g}^{\prime \prime}\right] \cdot\left[H g_{I^{\prime \prime}}\right]\right) .
\end{aligned}
$$

Here $D_{I}, D_{V}$ are diffusion coefficients of mercury interstitials and vacancies, accordingly; $K_{F}$, the reaction constant; angular brackets designate concentration of the appropriate defects.

Let's be limited to approximation of quite deep mercury diffusion when the diffusion terms in the left sides of Eqs. (1) are small in comparison with local terms in the right sides of the equations. In this case a method of stationary concentration can be applied [11], and distribution of electrical potential $\varphi$ can be assumed as quasiequilibrium: $\varphi=-(k T / e) \cdot \ln \left(p / p_{0}\right)$. Accordingly, Eqs. (1) can be written in such kind:

$$
\begin{aligned}
& \frac{\partial}{\partial t}\left[V_{H g}^{\prime \prime}\right]-\frac{\partial}{\partial t}\left[H g_{I}^{\prime \prime}\right]-\frac{\partial^{2}}{\partial z^{2}}\left(D_{V}\left[V_{H g}^{\prime \prime}\right]-D_{I}\left[H g_{I}^{\prime \prime}\right]\right)- \\
& -2 \frac{\partial}{\partial z}\left[\left(D_{V}\left[V_{H g}^{\prime \prime}\right]+D_{I}\left[H g_{I}^{\prime \prime}\right]\right) \frac{1}{p} \frac{\partial p}{\partial z}\right]=0 ; \\
& {\left[V_{H g}^{\prime \prime}\right] \cdot\left[H g_{I}^{\prime \prime}\right]=K_{F} .}
\end{aligned}
$$

If the temperature is high enough $(T>570 \mathrm{~K})$, so that the mercury vacancies prevail of other defects [7-8], under such condition the first equation can be simplified a little, neglecting the derivative $\partial\left[\mathrm{Hg}_{I}^{\prime \prime}\right] / \partial t$.

Edge conditions to Eqs. (2) are dependent on a considered problem. In particular, in a case of $\mathrm{Hg}$ diffusion in a heterogeneous MCT crystal these conditions can be written down on the basis of the following experimental fact. It is known, that because of high mobility of the mercury interstitials a sharp border arises at some depth $l$ at $\mathrm{Hg}$ diffusion into as-grown MCT crystals, sharing annealed homogeneous external part and not annealed heterogeneous core of the sample [10]. At these conditions the concept of effective $\mathrm{Hg}$ diffusion coefficient can be entered, having defined it as

$$
D_{H g}^{*}=l^{2} / t
$$

where $t$ there is the annealing duration, and $D_{H g}^{*}$ at enough deep $\mathrm{Hg}$ diffusion is independent of time [11-12]. Accordingly, the edge conditions to (1)-(2) get a kind [10]:

$\left.\left[H g_{I}^{\prime \prime}\right]\right|_{z=0}=\left[H g_{I}^{\prime \prime}\right]_{\mathrm{S}} ;\left.\quad\left[V_{H g}^{\prime \prime}\right]\right|_{z=l}=\left[V_{H g}^{\prime \prime}\right]_{0} ;$

where $\left[\mathrm{Hg}_{I}{ }^{\prime \prime}\right]_{S}$ is $\mathrm{Hg}_{I}{ }^{\prime \prime}$ concentration at the surface which is equal to equilibrium interstitial concentration under the given external conditions; $\left[V_{H g}^{\prime \prime}\right]_{0}$, the vacancy concentration in the core.

For $\mathrm{Hg}$ diffusion in a homogeneous unlimited layer of thickness $d$ the edge conditions get another kind [11]:

$$
\left.\left[H g_{I}^{\prime \prime}\right]\right|_{z=0}=\left[H g_{I}^{\prime \prime}\right]_{\mathrm{S}} ;\left.\quad\left[H g_{I}^{\prime \prime}\right]\right|_{z=d}=\left[H g_{I}^{\prime \prime}\right]_{\mathrm{S}} ;
$$

if mercury diffuses into a semi-infinite space $(d \rightarrow \infty)$, the edge conditions again get a kind (4) where the second of them is written down for $z \rightarrow \infty$ instead of $z=l$.

Eqs. (2) generally are solved only by numerical methods. However at some restrictions all of them suppose the approximated analytical integration and finding effective diffusion coefficient $D_{\mathrm{Hg}}^{*}$. In particular, it concerns to a case of deep mercury diffusion into a heterogeneous MCT crystal at $\left[V_{H g}{ }^{\prime \prime}\right]_{\mathrm{S}}<<\left[V_{H g}{ }^{\prime \prime}\right]_{0}$, that is well realized at $T<700 \mathrm{~K}[3 ; 8]$.

Let's consider, that $\left[\mathrm{VHg}^{\prime \prime}\right]_{0}$ vacancy concentration in the heterogeneous crystal core is constant and equal to their concentration at the Te-saturated conditions. Then, taking into account independence $D_{\mathrm{Hg}}^{*}$ of time at a big depth of mercury penetration [11-12], the first equation from Eqs. (2) supposes standard for the diffusion problem transition from two independent variables $(z, t)$ to one $(\xi=z / \sqrt{t})$. After such replacement the order of the Eqs. (2) can be reduced. Choosing the edge conditions as (4), 


\section{V.V. Bogoboyashchyy et al.: Diffusion and mobility of native point defects ...}

we shall obtain by such way a density of mercury diffusion flow:

$$
\begin{aligned}
& J_{H g}(z)=J_{H g}(l)+\frac{D_{H g}^{*}}{2 l^{2}} \int_{z}^{l} \xi \frac{d}{d \xi}\left(\left[V_{H g}^{\prime \prime}\right]-\left[H g_{I}^{\prime \prime}\right]\right) d \xi= \\
& =J_{H g}(l)+\left.\frac{D_{H g}^{*}}{2 l^{2}}\left[\xi\left(\left[V_{H g}^{\prime \prime}\right]-\left[H g_{I}^{\prime \prime}\right]\right)\right]\right|_{z} ^{l}- \\
& -\frac{D_{H g}^{*}}{2 l^{2}} \int_{z}^{l}\left(\left[V_{H g}^{\prime \prime}\right]-\left[H g_{I}^{\prime \prime}\right]\right) d \xi .
\end{aligned}
$$

where $J_{\mathrm{Hg}}(l)=\Delta_{\mathrm{Te}}(S) D_{\mathrm{Hg}}{ }^{*} / 2 l$, that follows from definition (3) and conditions of preservation of amount of atomic sites and $\mathrm{Hg}$ atoms at Te-excess annihilation: $J_{\mathrm{Hg}}(l) d t=$ $=\Delta_{\mathrm{Te}}(S) d l$.

After integration of Eq. (6) in limits from 0 up to $l$ the following one is obtained:

$$
\begin{aligned}
& D_{V}\left[\left[V_{H g}^{\prime \prime}\right]_{0}+2\left(\sqrt{n_{i}^{2}+\left[V_{H g}^{\prime \prime}\right]_{0}^{2}}-\sqrt{n_{i}^{2}+\left[V_{H g}^{\prime \prime}\right]_{S}^{2}}\right)\right]+ \\
& +D_{I}\left[H g_{I}^{\prime \prime}\right]_{S}\left(1+\frac{\left[V_{H g}^{\prime \prime}\right]_{S}}{n_{i}} \times\right. \\
& \left.\times \ln \left[\frac{\sqrt{n_{i}^{2}+\left[V_{H g}^{\prime \prime}\right]_{S}^{2}}+n_{i}}{\sqrt{n_{i}^{2}+\left[V_{H g}^{\prime \prime}\right]_{S}^{2}}-n_{i}} \cdot \frac{\sqrt{n_{i}^{2}+\left[V_{H g}^{\prime \prime}\right]_{0}^{2}}-n_{i}}{\sqrt{n_{i}^{2}+\left[V_{H g}^{\prime \prime}\right]_{0}^{2}}+n_{i}}\right]\right)= \\
& =\frac{1}{2} D_{H g}^{*}\left[\Delta_{T e}(S)+\int_{0}^{l}\left(\frac{\xi}{l}\right)^{2} \frac{d}{d \xi}\left(\left[V_{H g}^{\prime \prime}\right]-\left[H g_{I}^{\prime \prime}\right]\right) d \xi\right] .
\end{aligned}
$$

Here $\Delta_{T e}(S)$ is the average Te excess as precipitates; sub-indexes $S$ and 0 designate the defect concentration, accordingly, near to a crystal surface and in the initial state; $\left[V_{\mathrm{Hg}}{ }^{\prime \prime}\right]_{S}=K_{F} /\left[\mathrm{Hg}_{I}{ }^{\prime \prime}\right]_{S}$.

In a case when $\left[V_{\mathrm{Hg}}{ }^{\prime \prime}\right]_{S}<<\left[V_{\mathrm{Hg}}{ }^{\prime \prime}\right]_{0}$, mercury interstitial concentration decreases from $\left[\mathrm{Hg}_{I}{ }^{\prime \prime}\right]_{S}$ at $z=0$ down to $\left[\mathrm{Hg}_{I}{ }^{\prime \prime}\right]_{0}$ at $z=l$ almost linearly $[10-11]$. At these conditions the integral in the right side of Eq. (7) is equal to $\left[V_{\mathrm{Hg}}{ }^{\prime \prime}\right]_{0}$ as the first approximation, in view of the action mass law $\left[\mathrm{Hg}_{I}{ }^{\prime \prime}\right] \cdot\left[V_{\mathrm{Hg}}{ }^{\prime \prime}\right]=K_{F}$. Taking into account, that $\left[V_{\mathrm{Hg}}{ }^{\prime \prime}\right]_{S}<<n_{i}$ at $T<700 \mathrm{~K}$ [8], the next estimation is obtained for $\mathrm{Hg}$ effective diffusion coefficient within framework of such approximation for Eq. (7):

$$
\begin{aligned}
& D_{H g}^{*} \approx \frac{2}{\Delta_{T e}}\left\{D_{V}\left[\left[V_{H g}^{\prime \prime}\right]_{0}+2\left(\sqrt{n_{i}^{2}+\left[V_{H g}^{\prime \prime}\right]_{0}^{2}}-n_{i}\right)\right]+\right. \\
& +D_{I}\left[H g_{I^{\prime \prime}}\right]_{S} \times \\
& \left.\times\left(1+\frac{\left[V_{H g}^{\prime \prime}\right]_{S}}{n_{i}} \ln \left[\frac{4 n_{i}^{2}}{\left[V_{H g}^{\prime \prime}\right]_{S}^{2}} \cdot \frac{\sqrt{n_{i}^{2}+\left[V_{H g}^{\prime \prime}\right]_{0}^{2}}-n_{i}}{\sqrt{n_{i}^{2}+\left[V_{H g}^{\prime \prime}\right]_{0}^{2}}+n_{i}}\right]\right)\right\} . \\
& S Q O, 6(1), 2003
\end{aligned}
$$

where $\Delta_{\mathrm{Te}}=\Delta_{\mathrm{Te}}(S)+\left[V_{\mathrm{Hg}}{ }^{\prime \prime}\right]_{0}$ is the total initial tellurium excess in the sample.

\section{Determination of high-temperature mercury vacancy diffusion coefficient}

The model offered here was used for determination of the vacancy diffusion coefficient at high temperatures on the basis of the data submitted in Ref. [13].

In Ref. [13] structures of mercury vacancy diffusional distributions in thick bulk MCT plates $(x \sim 0.2)$ were experimentally investigated. The structures were obtained by annealing the plates in mercury vapour ambient in the temperature range $573-690 \mathrm{~K}$. Vacancy concentration in the plates was determined by the optical method offered in $[11 ; 15]$. This method is based on data of transmission measurements for radiation of a gas laser (wavelength $\lambda=10.6 \mu \mathrm{m}$ ), focused in a spot of diameter $100 \mu \mathrm{m}$. The vacancy concentration $\left[V_{H g}{ }^{\prime \prime}\right]$ was determined on these data in the probed areas of the sample. The error of such method was about $3 \cdot 10^{15} \mathrm{~cm}^{-3}$ at $\left[V_{\mathrm{Hg}}{ }^{\prime \prime}\right]<10^{17} \mathrm{~cm}^{-3}$, and it did not exceed $3 \%$ at $\left[V_{H g}{ }^{\prime \prime}\right]>10^{17} \mathrm{~cm}^{-3}[13]$.

The majority of the crystals investigated in Ref. [13], contained Te excess as precipitates. Annealing duration for such crystals was sufficient for formation of a homogeneous layer of thickness $l \sim 0.1 \mathrm{~cm}$; thus a heterogeneous core layer of thickness not less than $0.1 \mathrm{~cm}$ was kept inside each sample. One crystal was homogeneous and stoichiometric in the initial state. Distribution of mercury vacancies at $\mathrm{Hg}$ out-diffusion was studied there at high temperature $(677 \mathrm{~K})$ and low mercury partial pressure $(0.046 \mathrm{~atm})$. Some characteristics of the samples are given in Table 1 . More detailed annealing modes and measurement technique are presented in Refs. [8; 13].

Further mercury vacancy diffusion coefficient was determined on these data by fitting the experimental structures within framework of the model offered here. Distribution of the vacancies in the heterogeneous crystals was compared to results of the calculations executed by a numerical solution of Eqs. (2) at edge conditions (4). The vacancy diffusion coefficient $D_{V}$ was considered as the fitting parameter; other parameters of the theory $\left(\Delta_{\mathrm{Te}}, D_{I}\right.$ $\left[\mathrm{Hg}_{I}{ }^{\prime \prime}\right]_{S}$ and $\left.\left[V_{\mathrm{Hg}}{ }^{\prime \prime}\right]_{\mathrm{S}}\right)$ were determined independently on the annealing conditions and $\mathrm{Hg}$ penetration depth; data of Refs. [8; 16] were used for this. The results of such fitting for samples 1 and 3 are given in Fig. 1. Results of calculation of the vacancy distribution obtained at optimum $D_{V}$ values, are shown there by solid curves. It is visible, that settlement structures will well be coordinated to results of measurements. For comparison the structures calculated at $D_{V}=0$, are also shown in Fig. 1 (the shaped curves), that shows sufficient sensitivity of the method. The error of $D_{V}$ measurements by this method did not exceed $10 \%$ for these two samples.

In a case of mercury out-diffusion from the homogeneous crystal (see Fig. 2) resolution is a little bit worse, however it nevertheless allows to estimate $D_{V}$ to within $25 \%$. The vacancy diffusion mechanism was showed there 


\section{V.V. Bogoboyashchyy et al.: Diffusion and mobility of native point defects ...}

Table 1. Properties of the samples and annealing modes.

\begin{tabular}{lllllllllll}
\hline \hline $\mathrm{NN}$ & $x$ & $d, \mu \mathrm{m}$ & $N_{p}, \mathrm{~cm}^{-3}$ & $\Delta_{T e}, \mathrm{~cm}^{-3}$ & $T_{a}, \mathrm{~K}$ & $P_{\mathrm{Hg}}, \mathrm{atm}$ & $t, \mathrm{~h}$ & $l, \mu \mathrm{m}$ & $D_{I}\left[\mathrm{Hg}_{I}{ }^{\prime}\right]_{\mathrm{S}}, \mathrm{cm}^{-4} \mathrm{~s}^{-1}$ & {$\left[V_{H g}\right]_{\mathrm{S}}, \mathrm{cm}^{-3}$} \\
\hline 1 & 0.22 & 3580 & $10^{7}$ & $7.6 \cdot 10^{17}$ & 690 & 2.6 & 65 & 1350 & $2.13 \cdot 10^{10}$ & $1.15 \cdot 10^{16}$ \\
\hline 2 & 0.25 & 4650 & $10^{7}$ & $7.4 \cdot 10^{17}$ & 660 & 1.6 & 120 & 1210 & $1.10 \cdot 10^{10}$ & $4.2 \cdot 10^{15}$ \\
\hline 3 & 0.22 & 3350 & $10^{7}$ & $1.15 \cdot 10^{18}$ & 573 & 0.015 & 672 & 1000 & $4.32 \cdot 10^{7}$ & $2.7 \cdot 10^{15}$ \\
\hline \hline & 0.21 & 2800 & 0 & $<10^{14}$ & 677 & 0.046 & 4 & - & $4.8 \cdot 10^{8}$ & $2.5 \cdot 10^{17}$ \\
\hline
\end{tabular}
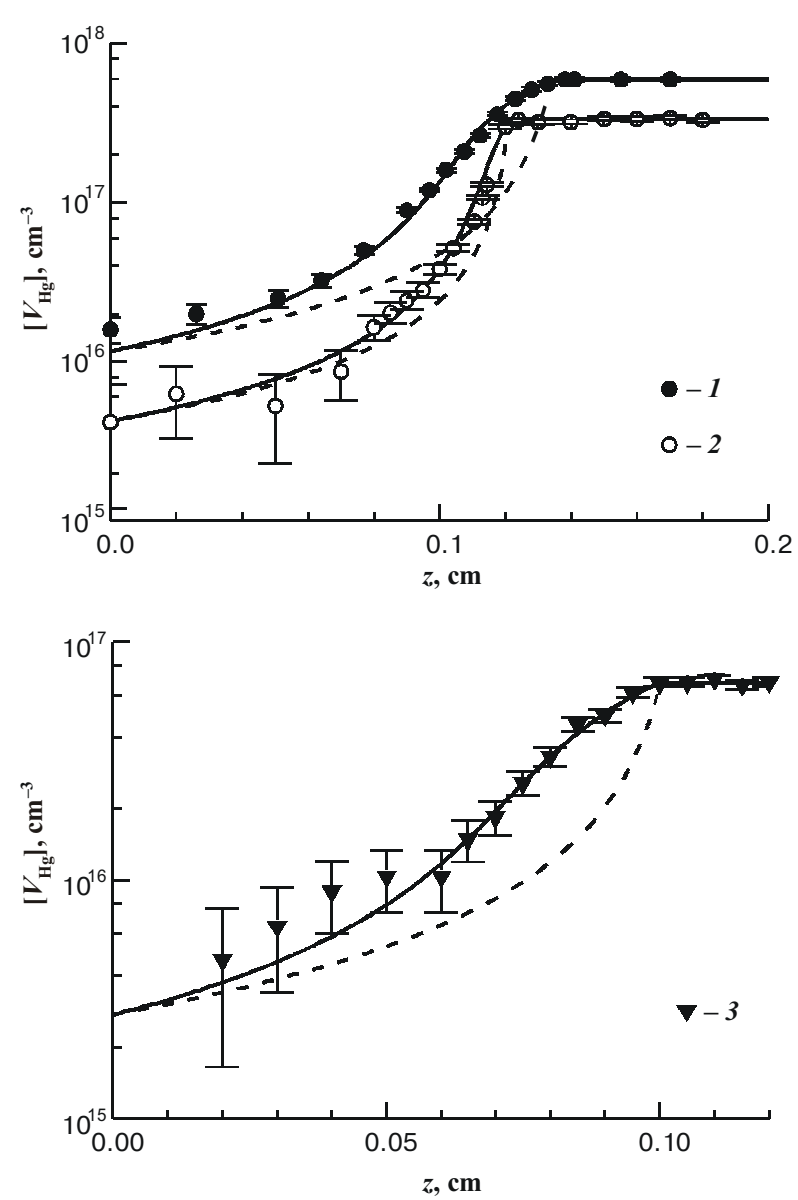

Fig. 1. Mercury vacancy distribution in initially heterogeneous $\mathrm{Hg}_{0.8} \mathrm{Cd}_{0.2} \mathrm{Te}$ crystals after mercury in-diffusion (the number of a point is the number of corresponding sample in Table 1). Points the data of measurements; solid lines - results of calculations under conditions of Table 1; shaped lines - results of calculation at $D_{V}=0$.

only near to a surface where $\mathrm{Hg}_{I}{ }^{\prime \prime}$ concentration was low enough.

$D_{V}$ values found in this way, are given in Fig. 3. They are well described by Arrhenius law:

$D_{V}=0.0063 \exp \left(-0.85 \mathrm{eV} / k_{B} T\right) \mathrm{cm}^{2} / \mathrm{s}$.

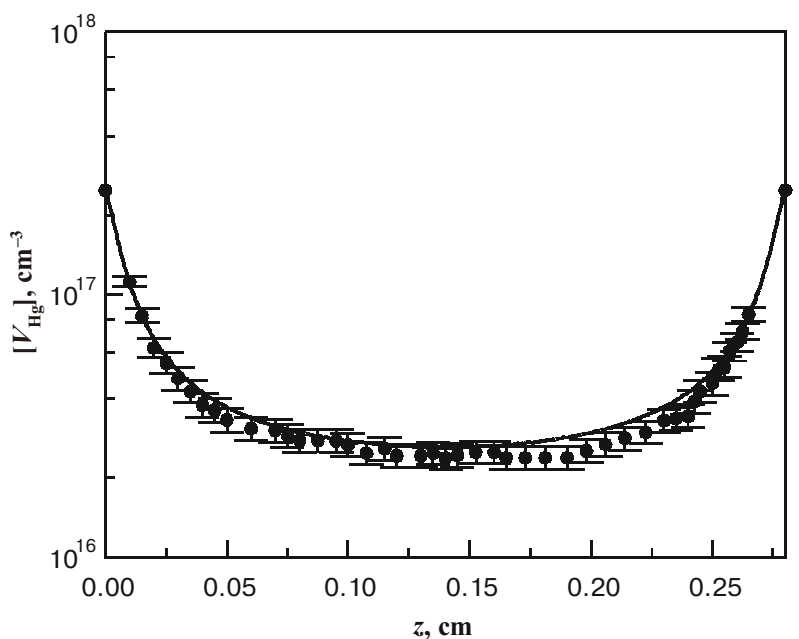

Fig. 2. Mercury vacancy distribution in initially homogeneous $\mathrm{Hg}_{0.8} \mathrm{Cd}_{0.2} \mathrm{Te}$ crystal after mercury out-diffusion (sample 4 in Table 1). Points - the data of measurements; solid lines - results of calculations under conditions of Table 1 .

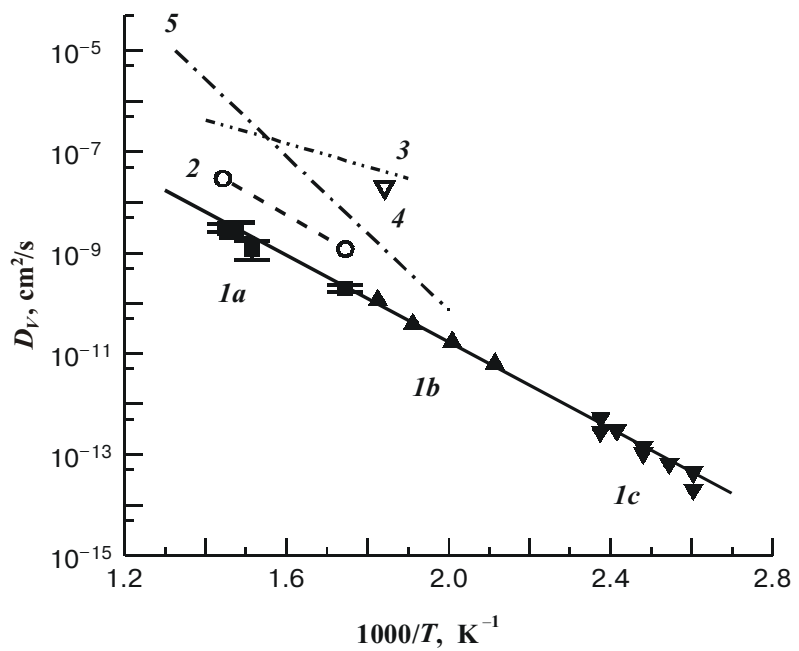

Fig. 3. Mercury vacancy diffusion coefficient in $\mathrm{Hg}_{0.8} \mathrm{Cd}_{0.2} \mathrm{Te}$ crystals. 1 - the data of present investigations $(I a-$ high temperature mercury diffusion; $l b$ - vacancy coagulation in the asgrown MCT crystals; $l c$ - vacancy coagulation in the pre-annealed MCT crystals); 2 - the data [2]; 3 - the data [10]; 4 - the data [12]; 5 - the data [17]. 


\section{V.V. Bogoboyashchyy et al.: Diffusion and mobility of native point defects ...}

\section{Estimations of low-temperature mercury vacancy diffusion coefficient}

Determination of $\mathrm{Hg}$ vacancy diffusion coefficient on their diffusional distribution in practice is possible only at enough high temperature when mercury penetrates into a MCT sample enough deeply. At low temperatures $D_{V}$ can be appreciated on kinetics of local processes of defect transformation [14]. Such experiment was executed in Ref. [14] where rate of mercury vacancy sedimentation into tellurium precipitates was studied at temperatures from 384 up to $548 \mathrm{~K}$. It has been shown there, that an initial stage of the process is described by an equation of quasi-chemical reaction of the second order:

$$
\frac{d}{d t}\left[V_{H g}\right]=-k_{2}\left[V_{H g}\right]^{2}
$$

where $k_{2}$ is the reaction rate constant.

Feature of this process is, that parameters of the Arrhenius law: $k_{2}=k_{20} \exp \left(-E_{a} / k_{B} T\right)-$ strongly depend on the initial crystal state. Namely: $E_{a}=0.60 \mathrm{eV}$ and $k_{20}=2 \cdot 10^{-16} \mathrm{~cm}^{3} / \mathrm{s}$ in a case of as-grown MCT crystals, and $E_{a}=0.71 \mathrm{eV}$ and $k_{20}=2.4 \cdot 10^{-14} \mathrm{~cm}^{3} / \mathrm{s}$ in a case of the crystals, pre-annealed at $T=873 \mathrm{~K}$ and $P_{\mathrm{Hg}}=2$ atm.

According to offered in Ref. [14] model, such vacancy coagulation kinetics features testifies to the next. The process proceeds as formation of a double mercury vacancy from two single mercury vacancies adsorbed with a precipitate, and rate of this reaction is limited with the adsorption rate. For such coagulation mechanism, according to [14],

$$
D_{V}=\frac{K_{1} k_{2}}{8 \pi R N_{p}} \exp \left(\frac{\Delta E}{k_{B} T}\right),
$$

where $\Delta E=2 e^{2} /\left(\varepsilon_{S} R\right)$ is the minimal energy of repulsing the adsorbed single vacancies; $R$, the average radius of a precipitate; $N_{p}$, the precipitate concentration; $\varepsilon_{S}$, the static dielectric constant; $K_{1}$, the reaction constant for vacancy adsorption by a precipitate.

The reaction constant $K_{1}=K_{10} \exp \left[-\Delta H_{S} /\left(k_{B} T\right)\right]$, where $K_{10} \approx N_{0}=1.48 \cdot 10^{22} \mathrm{~cm}^{-3}$ is the concentration of the cationic sites; $\Delta H_{S}$, the adsorption heat [14]. Precipitate concentration $N_{p}$ can be easily found under the obvious formula $N_{p}=\Delta_{T e}(S) v_{T e} \cdot 3 /\left(4 \pi R^{3}\right)$, where $v_{\mathrm{Te}}=$ $M_{T e} / \rho_{T e}=3.4 \cdot 10^{-23} \mathrm{~cm}^{3}$ is the specific volume per atom in the Te precipitate $\left(M_{\mathrm{Te}}\right.$ and $\rho_{\mathrm{Te}}$ are the atomic mass and the density of tellurium, accordingly). Then substituting this equations into Eq. (11) give:

$D_{V}=\frac{N_{0} k_{2} R^{2}}{6 \Delta_{T e}(S) v_{T e}} \exp \left(-\frac{\Delta H_{S}-\Delta E}{k_{B} T}\right)$,

According to Eq. (12), for estimation $D_{V}$ on $k_{2}$ coagulation rate constant, the average precipitate size $R$, the tellurium excess as precipitates $\Delta_{T e}(S)$ and also the adsorption heat $\Delta H_{S}$ in the investigated crystals are required to know. Therefore the microstructure of as-grown MCT crystals and the samples, pre-annealed at $873 \mathrm{~K}$ and water quenched, was investigated here by a transmission electronic microscopy method. In Fig. $4(\mathrm{a}, \mathrm{b})$ the images are given, obtained at enlargement $\times 2 \cdot 10^{5}(\mathrm{a})$ and $\times 5 \cdot 10^{5}(\mathrm{~b})$. Microscopic tellurium inclusions are specified by arrows in these images. It is visible, that the characteristic precipitate size $R$ is about $15 \mathrm{~nm}$ in the as-grown sample whereas in the pre-annealed sample it is less on the order of magnitude ( $R \approx 1.5 \mathrm{~nm}$ ).

Tellurium excess $\Delta_{T e}(S)$ was estimated in the asgrown crystals on effective mercury diffusion coefficient $D_{\mathrm{Hg}}{ }^{*}$ and was about $\Delta_{T e}(S) \approx 8 \cdot 10^{17} \mathrm{~cm}^{-3}$ (see Table 1 ). The tellurium excess in the samples annealed at $873 \mathrm{~K}$ and $P_{\mathrm{Hg}}=2$ atm was estimated on a difference of the equilibrium vacancy concentration at annealing (about $1.65 \cdot 10^{18} \mathrm{~cm}^{-3}$ on the data [3]) and active vacancy concentration after cooling $\left(3 \ldots 4 \cdot 10^{17} \mathrm{~cm}^{-3}\right): \Delta_{T e}(S) \approx$ $\approx 1.2 \cdot 10^{18} \mathrm{~cm}^{-3}$. In Fig. 3 (points $1 \mathrm{~b}$ and $1 \mathrm{c}$ ) the results of calculations $D_{V}$ are shown, executed at the mentioned above values of $R$ on the basis of Eq. (12) provided that $\Delta H_{S}=0.34 \mathrm{eV}$. It is visible, that results of calculations
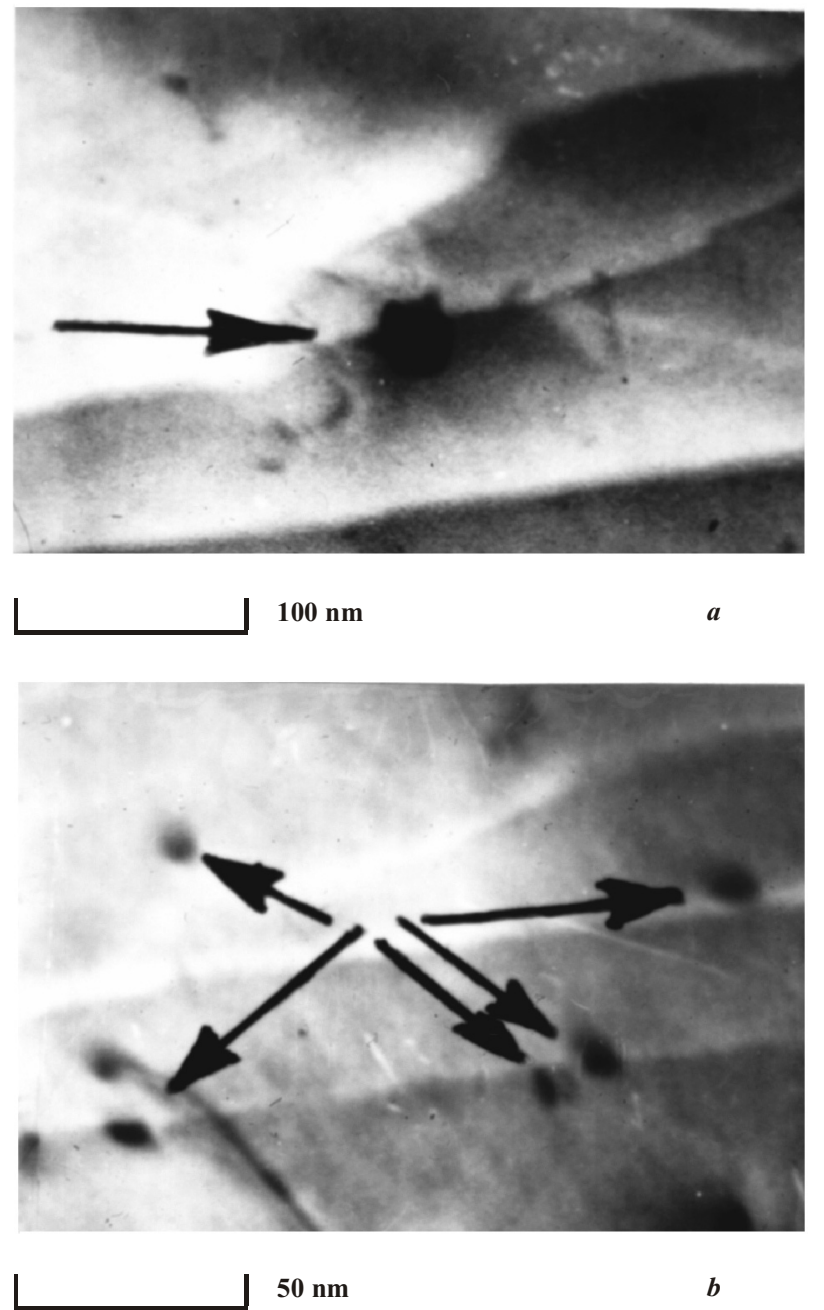

Fig. 4. TEM images of as-grown $(a)$ and pre-annealed at $T=873 \mathrm{~K}$ and $P_{\mathrm{Hg}}=2 \mathrm{~atm}(b) \mathrm{Hg}_{0.8} \mathrm{Cd}_{0.2}$ Te crystals. 


\section{V.V. Bogoboyashchyy et al.: Diffusion and mobility of native point defects ...}

will well be coordinated to the data of high temperature $D_{V}$ measurements (points 1a) for both types of crystals, and the fitted value $\Delta H_{S}$ will be coordinated to typical values of adsorption heat.

\section{Discussion}

The model offered here generalizes theories [10-13] on a case of mercury diffusion in a gradient of the native defect concentration in the narrow-gap MCT crystals with any ratio between intrinsic carriers concentration $n_{i}$, the mercury vacancy concentration $\left[V_{\mathrm{Hg}}{ }^{\prime \prime}\right]_{0}$ and tellurium excess $\Delta_{\mathrm{Te}}(S)$. As follows from Eq. (6), the diffusion flow density $J_{\mathrm{Hg}}$ generally varies with depth because of annihilation of mercury interstitials with the mercury vacancies in the annealed homogeneous part of the crystal. This conclusion contradicts a substantive provision on which the theory [10] is based. Nevertheless, it is visible, that the mercury flow can be considered as uniform on depth if $\Delta_{\mathrm{Te}}(S)>>\left[V_{\mathrm{Hg}}{ }^{\prime \prime}\right]_{0}$ in the crystal core. It limits applicability of model [10] with rather low temperatures when such inequality is holding true.

Other conclusion following from this model, is, that the account of the electrical drift results in essential increase in $D_{\mathrm{Hg}}{ }^{*}$, if $\left[V_{\mathrm{Hg}}{ }^{\prime \prime}\right]_{0}>n_{i}$ (without taking into account such drift $D_{\mathrm{Hg}}{ }^{*} \approx 2\left\{D_{V}\left[V_{\mathrm{Hg}}{ }^{\prime \prime}\right]_{0}+D_{I}\left[\mathrm{Hg}_{I}{ }^{\prime \prime}\right]_{\mathrm{S}}\right\} / \Delta_{\mathrm{Te}}$ [13]). It is remarkable, that within framework of the model offered here, as well as in Ref. [13], the effective $\mathrm{Hg}$ diffusion coefficient in a heterogeneous MCT crystal is inversely proportional to the total tellurium excess $\Delta_{T e}$ in its heterogeneous part, irrespective of the kind of its realization. It fully complies with results of the experiment executed in Ref. [16].

Let's note, that the frequency factor in Arrhenius law (9) is close to its expected theoretical value on the order of magnitude. Really, for cationic vacancies in diamondlike crystals $D_{V 0}=Z a^{2} \Gamma_{0} / 6$ [18], where $Z=12$ is the number of the nearest cationic neighbors; $a$, the lattice parameter $(a=0.648 \mathrm{~nm}$ for MCT $) ; \Gamma_{0}$, the characteristic frequency. If to neglect an entropy factor and to put, that $\Gamma_{0} \approx \omega_{\mathrm{TO}} / 2 \pi[18]$, then $D_{V 0} \approx 0.034 \mathrm{~cm}^{2} / \mathrm{s}$. The experimental $D_{V 0}$ value $\left(0.0063 \mathrm{~cm}^{2} / \mathrm{s}\right)$ is a little bit less. Probably, that is because of power inequality of different configurations of $\mathrm{Hg}$ and $\mathrm{Cd}$ atoms around $\mathrm{V}_{\mathrm{Hg}}$ " so that only a part of such configurations is used for the jumps.

Comparison of the result obtained here with the data of other investigations (see Fig. 3) shows, that the values $D_{V}$ are essentially low, than it was considered earlier. The detailed reasons of this divergence were specified in the previous study [13]; they are connected to application in [10-12] inadequate models for adjustment of the experimental data.

\section{Conclusions}

Thus, the electric field created by the charged native defects in MCT crystal at mercury diffusion in a gradient of concentration, essentially accelerates this process at high temperatures and low partial mercury pressures because of great defect concentration and the double electric charge of the defects. Therefore the mercury vacancy diffusion coefficient, found experimentally in view of this effect, appears rather small than it was considered earlier in $[2 ; 10 ; 12-13]$, and its contribution in the mercury diffusion flow at high partial mercury pressures and $T<690 \mathrm{~K}$ can be neglected.

\section{References}

1. A. Rogalski, Infrared detectors, Gordon and Breach Science Publishers, The Netherlands (2000).

2. D. Shaw and P. Capper, Conductivity type conversion in $\mathrm{Hg}_{1-\mathrm{x}} \mathrm{Cd}_{\mathrm{x}} \mathrm{Te} / /$ J. Mater. Sci.: Materials in Electronics 11, pp. 169-177 (2000)

3. H.R. Vydyanath, Lattice defects in semiconducting $\mathrm{Hg}_{1-\mathrm{x}} \mathrm{Cd}_{\mathrm{x}} \mathrm{Te}$ alloys. P. I. Defect structure of undoped and copper doped $\mathrm{Hg}_{0.8} \mathrm{Cd}_{0.2} \mathrm{Te} / /$ J. Electrochem. Soc.: SolidState Sci. and Technol. 128 (12), pp. 2609-2629 (1981).

4. H.F. Schaake, The existence region of the $\mathrm{Hg}_{1-\mathrm{x}} \mathrm{Cd}_{\mathrm{x}} \mathrm{Te}$ phase field // J. Electron. Mater. 14 (5), pp. 513-530 (1985).

5. H.R. Vydyanath and C.H. Hiner, Anneling behavior of undoped $\mathrm{Hg}_{0.8} \mathrm{Cd}_{0.2} \mathrm{Te}$ epitaxial films at low temperatures // J. Appl. Phys. 65 (8), pp. 3080-3088 (1989).

6. M. Wienecke, M. Schenk, and H. Berger, Native point defects in Te-rich p-type $\mathrm{Hg}_{1-\mathrm{x}} \mathrm{Cd}_{\mathrm{x}} \mathrm{Te} / /$ Semicond. Sci. and Technol. 8 (2), pp. 299-302 (1993).

7. M.A. Berding, M. van Schilfgaarde, and A. Sher, First-principles calculation of native defect densities in $\mathrm{Hg}_{0.8} \mathrm{Cd}_{0.2} \mathrm{Te}$ I/ Phys. Rev. B. 1 (3), pp. 1519-1534 (1994).

8. V.V. Bogoboyashchii, Concentration of equilibrium native defects in crystals of narrow-gap $\mathrm{Hg}_{1-\mathrm{x}} \mathrm{Cd}_{\mathrm{x}} \mathrm{Te}$ solid solutions on data of galvanomagnetic and optical measurements // Kondens. Sredy i Mezhfazn. Granicy. 2 (2), pp.132-137 (2000).

9. C.L. Jones, M.J.T. Quelch, P. Capper et al., Effect of annealing on the electrical properties of $\mathrm{Cd}_{\mathrm{x}} \mathrm{Hg}_{1-\mathrm{x}} \mathrm{Te} / / \mathrm{J}$. Appl. Phys. 53 (12), pp. 9080-9092 (1982).

10. H.F. Schaake, J.H. Tregilgas, J.D. Beck et al., The effect of low-temperature annealing on defects, impurities and electrical properties of $(\mathrm{Hg}, \mathrm{Cd}) \mathrm{Te} / /$ J. Vac. Sci. Technol. B. A3 (1), pp. 143-149 (1985).

11. V.V. Bogoboyashchii, A.I. Elizarov, V.I. Ivanov-Omskii et al., Kinetics of equilibration of $\mathrm{Cd}_{\mathrm{x}} \mathrm{Hg}_{1-\mathrm{x}} \mathrm{Te}$ crystals with mercury vapour // Fiz. and Tekhn. Poluprov. 19 (5), pp. 819-824 (1985).

12. S. Holander-Gleixner, H.G. Robinson, and C.R. Helms, Derivation of an analytical model to calculate junction depth in HgCdTe photodiodes // J. Appl. Phys. 83 (2), pp. 12991306 (1998).

13. V.V. Bogoboyashchyy, Study of diffusive distribution of mercury vacancies in $\mathrm{Hg}_{0.8} \mathrm{Cd}_{0.2} \mathrm{Te}$ single crystals // Functional materials. 8 (4), pp. 609-614 (2001).

14. V.V. Bogoboyashchyy, Mercury vacancies coagulation kinetics and mechanism in $\mathrm{Hg}_{0.8} \mathrm{Cd}_{0.2}$ Te crystals // Functional materials. 8 (2), pp. 280-285 (2001).

15. V.V. Bogoboyashchii, A.I. Elizarov, V.I. Ivanov-Omskii et al., Effect of a deviation from stoichiometry of composition of $\mathrm{Cd}_{\mathrm{x}} \mathrm{Hg}_{1-\mathrm{x}} \mathrm{Te}(\mathrm{x} \approx 0.2)$ crystals on $\mathrm{Hg}$ diffusion rate // Fiz. and Tekhn. Poluprov. 21 (8), pp.1462-1465 (1987).

16. V. Bogoboyashchiy, Interconsistent band structure of narrow-gap $\mathrm{Hg}_{1-\mathrm{x}} \mathrm{Cd}_{\mathrm{x}} \mathrm{Te}$ alloys obtained with taking into account far band influence // Proceedings SPIE 3486, pp. 325335 (1997).

17. M. Newbert and K. Jacobs // J. Cryst. Growth. 161, pp. 229 (1996).

18. Atomic Diffusion in Semiconductors. Ed. by D. Shaw, New York: Wiley (1974). 